\title{
New international Turner syndrome guideline: a multi-society feat
}

\author{
Claus H Gravholt ${ }^{1,2}$ and Philippe Backeljauw ${ }^{3}$ \\ ${ }^{1}$ Department of Endocrinology and Internal Medicine and Medical Research Laboratories, Aarhus University \\ Hospital, Aarhus, Denmark, '2Department of Molecular Medicine, Aarhus University Hospital, Aarhus, Denmark, \\ and ${ }^{3}$ Division of Pediatric Endocrinology, Cincinnati Children's Hospital Medical Center and University of Cincinnati \\ College of Medicine, Cincinnati, Ohio, USA
}

Correspondence should be addressed to $\mathrm{C} \mathrm{H}$ Gravholt

Email

ch.gravholt@dadlnet.dk

It is with great pleasure that we present the new international guidelines for the clinical care of Turner syndrome (TS) females-published in the current issue of the European Journal of Endocrinology (1). These guidelines are the result of the work of many specialists covering all aspects of the care of TS females throughout the entire life span. They are also due to the input of many involved societies, which has included specialists from the European Society for Endocrinology, Pediatric Endocrine Society, the Endocrine Society, the European Society for Pediatric Endocrinology, European Society of Human Reproduction and Embryology, the American Heart Association, the Society for Endocrinology and the European Society of Cardiology. In addition, specialists from yet other professional societies participated in work groups that developed the guidelines consensus statement. We also included patient advocate groups in all these working groups, aiming to include a voice of the TS patients throughout the entire process. Participating delegates thus came from many different backgrounds and this caused the guideline process to be an open, democratic and transparent endeavor, starting with simultaneous initial meetings in Europe and the United States, followed by a joint consensus meeting in Cincinnati, USA, in 2016. After this a writing group put the final document together, with all contributors approving the final guideline manuscript.

We also took a systematic evidence approach to the scientific literature and used the GRADE approach to evaluate four pertinent questions, which were: (1) What is the effect of growth-promoting treatment in TS? (2) What is the probability of achieving viable pregnancy after oocyte donation in TS? (3) What is the effect of blood pressure treatment on clinical outcomes in TS? and (4) What is the best estrogen replacement approach in TS? While we were able to answer the first two questions with reasonable certainty, we did not find enough scientific evidence to precisely answer questions concerning best practice on estrogen replacement

www.eje-online.org DOI: 10.1530/EJE-17-0540
(C) 2017 European Society of Endocrinology Printed in Great Britain in TS. Furthermore, it was clear that almost no research has addressed questions concerning treatment of hypertension (which occurs early and is common in TS). Thus, one of the conclusions of the guideline process is that there is a great need for additional investigation in a variety of areas to further improve the care of TS females.

The guidelines recommendations cover many areas. We discuss diagnosis and genetics, pinpointing what should be called TS and what should not be called TS. We also focus on delayed diagnosis and the frequent occurrence of non-diagnosis, suggesting new avenues for diagnosis. We discuss to include TS in newborn screening programs to avoid long diagnostic odysseys and non-diagnosis. Growth and puberty are key issues of concern, and we present new recommendations for optimal growth-promoting treatment and induction of puberty, when especially the age for pubertal induction is now recommended to be between 11 and 12 years. Concerning fertility, which adults with TS judge as the most important determinant of quality of life, several new recommendations are put forward. Many women with TS are now able to achieve pregnancy after oocyte donation, and the birth of a healthy child, if such a pregnancy is well planned and preceded by a thorough cardiovascular workup. We present detailed cardiovascular recommendations based on a wealth of new data coming from several centers around the world. Our review of the literature elucidated the frequent occurrence of congenital cardiac malformations including some previously described (bicuspid valves and coarctation of the aorta), but has broadened this to include entities like elongated aortic arch, aortic dilation and dilation of the branching arteries. We emphasize that magnetic resonance imaging or other similar techniques should be used much more liberally. We also discuss rigorous treatment of the frequently occurring hypertension, especially during pregnancy. We discuss the transition process from the pediatric to adult

Published by Bioscientifica Ltd. 
care and propose to strengthen this process. We present recommendations for appropriate care during adulthood while covering all known comorbidities that affect TS individuals. Neurocognitive impairment frequently affects individuals with TS and we present new operational recommendations for neuropsychological care.

We urge the creation of multidisciplinary clinics around the world and stress that TS individuals should be taken care of in such units. This will ensure pervasive care from childhood through adolescence into adulthood. We believe that centers around the world should implement policies to this end.

Have fun reading the guidelines!

Declaration of interest

The authors declare that there is no conflict of interest that could be perceived as prejudicing the impartiality of the research reported.

\section{Funding}

The Turner Syndrome guidelines were sponsored primarily by ESE, and co-sponsored by PES, ESPE and ES. Furthermore, ESHRE and ESC supported their own delegates for the meeting, and additional support was obtained from the AHA, the National Institute of Child Health and Human Development (NICHD), the National Center for Advancing Translational Sciences, Cincinnati Children's Hospital Medical Center's TS Foundation, as well as several advocacy groups (TS Society of the United States, the TS Global Alliance and the Turner Resource Network).

\section{Reference}

1 Gravholt CH, Andersen NH, Conway GS, Dekkers OM, Geffner ME, Klein KO, Lin AE, Mauras N, Quigley CA, Karen R et al. Clinical practice guidelines for the care of girls and women with Turner syndrome: proceedings from the 2016 Cincinnati International Turner Syndrome Meeting. European Journal of Endocrinology 2017177 G1-G70. (doi:10.1530/EJE-17-0430) 